\title{
Instrumental escape learning in the rat at 24-hour intertrial interval: Effects of magnitude and schedule of reinforcement
}

\author{
JEFFREY A. SEYBERT \\ University of Missouri-Kansas City, Kansas City, Missourl 64110 \\ and \\ RANDALL L. RIGBY and ROGER L. MELLGREN \\ University of Oklahoma, Norman, Oklahoma 73069
}

\begin{abstract}
Three experiments investigated the effects of magnitude and schedule of reinforcement and level of training in instrumental escape learning at a 24-h intertrial interval. In Experiment I, two magnitudes of reinforcement were factorially combined with two schedules of reinforcement (CRF and PRF). Under PRF, large reward produced greater resistance to extinction than did small reward, while the reverse was true under CRF. In Experiment II, two levels of acquisition training were factorially combined with three schedules of reinforcement (CRF, single-alternation, and nonalternated PRF). Patterned running was observed late in acquisition in the single-alternation extended-training condition. Resistance to extinction was greater for the nonalternated PRF condition than for the single-alternation condition following extended acquisition, and the reverse was true following limited acquisition. Experiment III confirmed the extinction findings of Experiment II. The results of all three experiments supported an analysis of escape learning at spaced trials in terms of Capaldi's (1967) sequential theory.
\end{abstract}

Although a large number of studies of escape training have utilized massed-trial procedures, there are surprisingly few published reports of escape learning experiments using wide spacing of trials. In the present experiments, we examine the effects of several variables on discrete-trial instrumental escape learning at 24-h intertrial intervals (ITI).

Franchina (1969) has reported a spaced-trial escape experiment using an intermittent shock procedure in a hurdle box. One of the shortcomings of the intermittent shock procedure, however, is that the absence of primary motivation on nonshock trials make shock and nonshock trials not strictly analogous to appetitive reinforced $(R)$ and nonreinforced $(\mathrm{N})$ trials. Empirical as well as theoretical statements based on such findings, therefore, may not be directly comparable to the shock-nonshock procedure. The present experiments used procedures for $\mathrm{R}$ and $\mathrm{N}$ trials analogous to those employed in appetitive instrumental conditioning. Specifically, a reinforced escape trial consisted of the application of the aversive stimulus (shock) to the subject in the start and run sections of the runway and the absence (or reduced level) of the aversive stimulus in the

The authors would like to thank Richard Larwig for his assistance in running the subjects. Requests for reprints should be sent to J. A. Seybert, Department of Psychology, C.B. Annex, University of Missouri-Kansas City, Kansas City, Missouri 64110. R. L. Rigby is now at the United States Military Academy, West Point, New York 10996. goalbox. A nonreinforced escape trial was similar to a reinforced escape trial, except that the start-run level of aversive stimulation was maintained in the goalbox. It should be noted that the duration of a "nonreinforced" goal event must necessarily be limited in this procedure because at some time after the subject enters the goalbox it must be removed. The present procedure may thus be more analogous to delay of reinforcement, but since the theoretical mechanisms which have been proposed to account for the effects of both nonreinforcement and delay are highly similar (Capaldi, 1967), we will use the nonreinforcement terminology.

\section{EXPERIMENT I}

With massed trials, magnitude and schedule of reinforcement have been shown to interact to determine resistance to extinction both for appetitive (e.g., Hulse, 1958) and aversive (Mellgren, Nation, \& Wrather, 1975) motivational conditions. Specifically, large reward magnitudes produce greater resistance to extinction $(\mathrm{Rn})$ than small reward magnitudes after partial reinforcement (PRF) training, and the opposite is the case after continuous reinforcement (CRF) training. Experiment I was designed to assess the combined effects of magnitude and schedule of reinforcement on resistance to extinction in spaced-trial escape learning. Magnitude of reinforcement was varied by differentially reducing the start- 
run shock level in the goalbox. Specifically, a .2-mA shock reduction served as small magnitude reinforcement and a .4-mA reduction served as large magnitude.

\section{Method}

Subjects. The subjects were 40 male, albino rats of the Sprague-Dawley strain purchased from the Holtzman Company. They were approximately 140 days old at the start of training and were randomly assigned to one of four groups ( $N=10 /$ group).

Apparatus. The apparatus was a straight alley runway manufactured by the Hunter Company. It was constructed of clear Plexiglas, had a grid floor, and was $150 \mathrm{~cm}$ long $\times 15 \mathrm{~cm}$ high $\times 9 \mathrm{~cm}$ wide. The alley was divided into a $30-\mathrm{cm}$ start section, a $90-\mathrm{cm}$ run section, and a $30-\mathrm{cm}$ goal section. All sections were separated by guillotine doors, and a cardboard insert painted with $1.9-\mathrm{cm}$-wide black and white vertical stripes, was attached to the outside of each section. The subjects' progress in the alley was measured by three $.01-\mathrm{sec}$ Standard timers: the start time clock was activated by a microswitch at the startbox door and stopped by a photocell, located $11 \mathrm{~cm}$ into the alley; the run time clock was started by the first photocell and stopped by a second photocell, located $11 \mathrm{~cm}$ in front of the goalbox; the goal time clock was started by the second photocell and stopped by a third photocell, located $9 \mathrm{~cm}$ inside the goalbox. Start, run, and goal speeds were obtained by converting the start, run, and goal times to reciprocals. In addition; the sum of the start, run, and goal times was converted to a reciprocal to obtain a total speed measure.

Shock was delivered automatically to the start and run sections of the alley by a Model 700 Grason-Stadler shock generator activated by the microswitch at the startbox door. Shock was delivered to the goalbox by a second shock generator of the same type also activated by the microswitch at the startbox door. Duration of shock and confinement time in the goalbox was regulated by an automatic timer mounted in the apparatus control panel. This apparatus was also used in Experiments II and III.

Procedure. Throughout the experiment, the rats were individually housed and maintained on an ad-lib schedule of food and water. Prior to the start of experimental training, each subject received two reinforced pretraining trials in the apparatus. During the experiment, the following procedure was employed on reinforced trials: the subject was placed in the startbox, and after 5 sec the start box door was raised, activating the first timer and the shock generator, which was set to deliver a .6-mA shock to the start and run sections of the runway. When the subject had traversed the runway and had entered the goalbox, in which either a .2- or. .4-mA shock was delivered by the second shocker, the goalbox door was closed and the subject was confined for $30 \mathrm{sec}$, after which it was removed to the carrying cage. The procedure on nonreinforced trials was the same as that on reinforced trials, except that the goalbox also was charged with a .6-mA shock. Reinforcement thus consisted of either a .2- or .4-mA reduction in shock ( $R$ ), while nonreinforcement (N) consisted of no reduction in the start-run shock level.

For the experiment proper, two reward magnitudes (Large, .4-mA shock reduction; and Small, .2-mA reduction) were factorially combined with two schedules of reinforcement (CRF and PRF). The PRF groups received a $50 \%$ schedule of reinforcement on the following schedule: RRNNRNRNNR. This schedule was repeated four times for a total of 40 acquisition trials. The CRF groups also received 40 acquisition trials. All groups were given one acquisition trial per day. The subjects were run in squads of eight, two from each group in a squad. Following acquisition training, all subjects received 28 extinction trials, one per day for 28 days. The procedure for extinction trials was the same as for $\mathrm{N}$ trials during acquisition for all three experiments reported here. In order to minimize any possible effects due to odor cues, the alley was thoroughly wiped following each trial in both acquisition and extinction for all three experiments.

\section{Results and Discussion}

Acquisition. The data from each alley section (i.e., start, run, goal, and total) for the last 4 days of acquisition (seen as point $\mathbf{A}$ in Figure 1) were combined into a single block, and separate analyses were performed on each measure. The only reliable differences appeared in total speeds where the magnitude main effect, $F(1,36)=15.50, p<.05$, and the Magnitude by Schedule interaction, $F(1,36)=$ $18.00, p<.05$, were significant (a .05 level of significance was used for all analyses and comparisons in the three experiments reported here).

Extinction. The extinction data from each alley section (shown in Figure 1) were combined into 4-day blocks, and separate analyses were performed on each measure. So that the total speeds in extinction would not be contaminated by the terminal acquisition differences, these data were transformed to a rate measure (Anderson, 1963) prior to analysis. The interaction of Schedule by Magnitude was significant for all measures, $\operatorname{Fs}(1,36)=33.24,9.85$, 8.40 , and 10.94 , for the start, run, goal, and total measures, respectively. Evaluation of these interac-

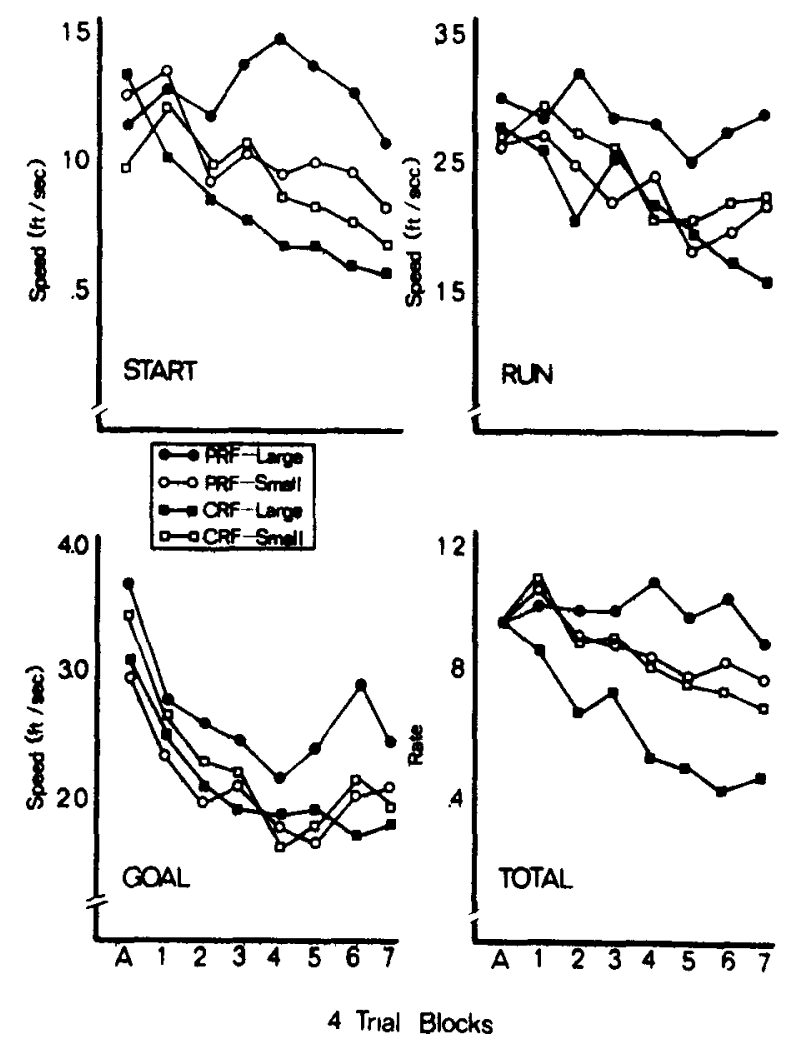

Figure 1. Mean speeds (for the start, run, and goal sections) and rate measure (for the total section) for the last 4 trials of acquisition and 28 trials of extinction, in 4-trial blocks. 
tions using simple main effects procedures revealed the following ordering for the groups in terms of resistance to extinction: start, large $P R F>$ small $\mathrm{PRF}=$ small $\mathrm{CRF}=$ large $\mathrm{CRF}$; run, large PRF $>$ small $\mathrm{CRF}=$ small $\mathrm{PRF}=$ large $\mathrm{CRF}$; goal, large $P R F>$ small $C R F=$ small $P R F=$ large CRF; total, large PRF $>$ small $P R F=$ small CRF $>$ large CRF. Thus, under PRF schedules, large reward generated more $\mathrm{Rn}$ than did small reward in all alley sections. On the other hand, when CRF was used, the results of the transformed total speed analysis indicated that small reward produced greater $\mathbb{R n}$ than did large reward. These results, in general, are in agreement with those from similar studies using massed trials (e.g., Hulse, 1958; Mellgren et al., 1975). It should be noted, however, that the present data provide no indication of the most appropriate theoretical mechanism to account for these findings, since the two major theoretical statements concerning the PREE, Capaldi's (1967) sequential theory, and Amsel's (1967) frustration theory, both can explain the interaction of magnitude and schedule. Experiments II and III were designed to explore further the matter of appropriate mechanism.

\section{EXPERIMENT II}

Although Capaldi's (1967) sequential theory has been quite successful in accounting for data from appetitive instrumental conditioning situations (e.g., Robbins, 1971), only recently has it been applied to aversive conditioning situations. A number of studies have demonstrated the importance of sequential variables in punishment procedures (e.g., Capaldi \& Levy, 1972; Dyck, Mellgren, \& Nation, 1974; Wroten, Campbell, \& Cleveland, 1974), while a few have supported the hypothesis that sequential variables operate in instrumental escape situations (e.g., Mellgren, et al., 1975; Seybert, Mellgren, Jobe, \& Eckert, 1974). Also, while some investigators (e.g., Amsel, 1967; Gonzalez \& Bitterman, 1969; Surridge \& Amsel, 1966) have suggested that sequential theory may not be appropriate for data collected at widely spaced trials, others (e.g., Jobe \& Mellgren, 1974; Mellgren \& Seybert, 1973; Seybert, Mellgren, \& Jobe, 1973) have presented data indicating that sequential theory can explain results from spaced-trial procedures. Experiment II addressed itself to both of these issues. Two reliable massed-trial sequential phenomena were investigated using procedures similar to those described for Experiment I. The first of these, patterned responding, or patterning, refers to a situation in which a regular, single-alternating (SA) schedule of $N$ and $R$ trials is given and subjects learn to run more slowly on $\mathrm{N}$ trials than on $\mathrm{R}$ trials. The second phenomenon, an interaction between reward schedule and level of training, is demonstrated when subjects receiving short $\mathrm{N}$ lengths (number of consecutive $\mathrm{N}$ trials followed by an $R$ trial) are more resistant to extinction than subjects receiving long $\mathrm{N}$ lengths following limited acquisition, while the reverse effect is observed following extended training. Both of these phenomena have been observed in appetitive (Capaldi, 1967) and escape (Seybert, et al., 1974) massed trial procedures.

A factorial design was used to investigate these sequential phenomena in the present spaced-trial instrumental-escape paradigm. Two levels of training, 12 and 60 acquistion trials, were factorially combined with three schedules of reinforcement, CRF, $50 \%$ partial reinforcement on a single alternation basis (SA), and $50 \%$ PRF with $\mathrm{N}$ lengths of $3(3 \mathrm{~N})$. If results from the spaced escape procedures are analogous to those from massed trial paradigms, subjects in the SA60 condition should learn to pattern while those in the SA-12 condition should not; Group SA-12 should show greater resistance to extinction than Group $3 \mathrm{~N}$ 12 , while Group $3 \mathrm{~N}-60$ should be more resistant to extinction than Group SA-60. In addition, each PRF group should be more resistant to extinction than the corresponding CRF group at each level of training.

\section{Method}

Subjects. The subjects were 60 male rats, 125 days old at the start of training. They were randomly assigned to one of six groups $(\mathrm{N}=10 /$ group $)$.

Procedure. The procedure for the present experiment was the same as for Experiment I, with several exceptions. The start and run sections were charged with a .5-mA shock. On reinforced trials, a .1-mA shock was delivered to the goalbox grid, and on nonreinforced trials, the shock level in the goalbox was .5 mA. The SA and $3 \mathrm{~N}$ groups received $50 \%$ PRF on the following schedules: SA, NRNRNRNRNRNR; 3N, RRNNNRRRNNNR. These schedules were used once for the 12-trial groups and repeated five times for the 60-trial groups. Acquisition training consisted of one trial per day for all groups. Pretraining trials for the 60-trial groups were conducted on Days 1 and 2 of the experiment; their acquisition training trials were given on Days 3-62. The 12-trial groups, which were transported to and from the experimental room and handled on Days 1-48, received their two pretraining trials on Days 49 and 50 and their acquisition training trials on Days 51-62. Thus, the rats were equated across groups for age, amount of handling, and amount of experience outside the home cage. They were run in squads of 12,2 from each group in each squad. Acquisition training was followed by 24 extinction trials, one per day for 24 days for all subjects.

\section{Results and Discussion}

Acquisition. The acquisition data were analyzed so that three factors could be examined: (1) patterning, (2) the course of acquisition for the 60-trial groups, and (3) overali terminal acquisition performance. The only evidence for patterning behavior appeared in the SA- 60 group. The rats in this group responded nondifferentially for approximately 45 trials, at which time they began to respond more slowly on 


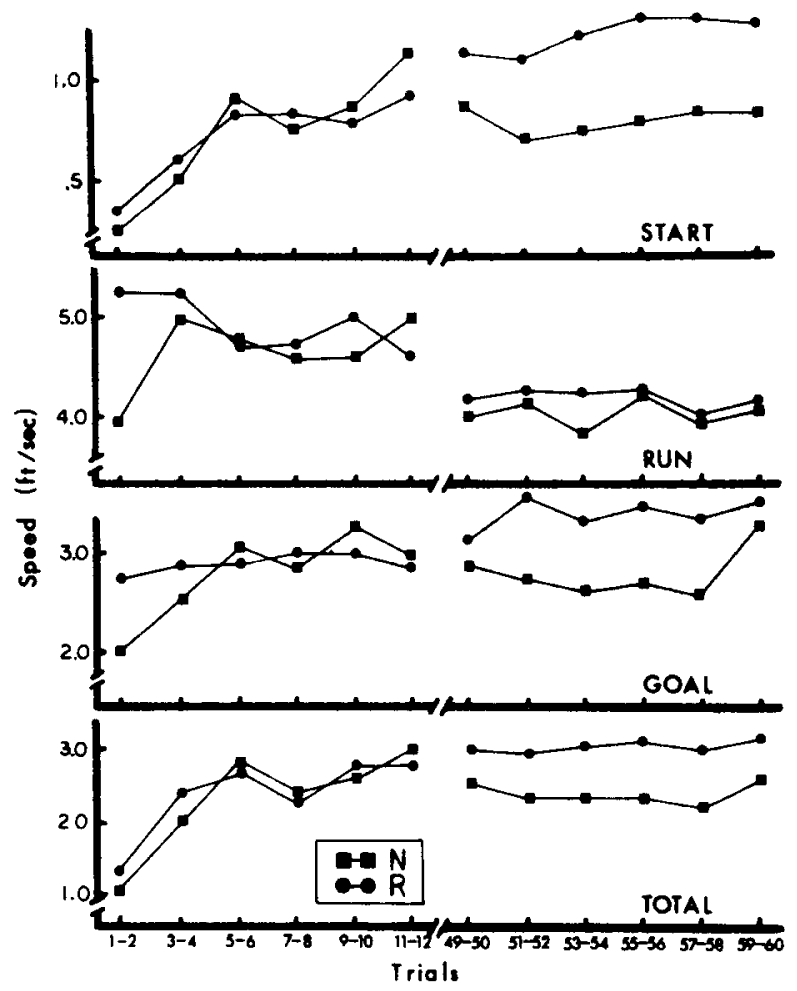

Figure 2. Mean speeds on reinforced $(R)$ and nonreinforced $(N)$ trials for the SA-60 group on Trials 1-12 and 49-60 of acquisition ( $N$ occurred on odd numbered days and $R$ on even numbered days).

$\mathrm{N}$ trials than on $\mathrm{R}$ trials (see Figure 2). Correlated $t$ tests on the last five $N$ and last five $R$ trials for the SA-60 trials group for start, run, and goal speed measures indicated that patterning occurred in start and goal, $\operatorname{ts}(9)=8.28,5.10$, respectively, but not in run, $t(9)=1.45, p>.10$. The occurrence of patterning in the present experiment is in agreement with a previous study (Capaldi \& Lynch, 1966) using a spaced-trial appetitive procedure.

The course of acquisition in all alley sections (shown in Figure 3 ) was examined by analyzing three six-trial blocks (Trials 1-6, 31-36, 55-60) for the three 60 -trial groups. The analysis revealed significant main effects for Blocks in the run and goal sections, Fs $(2,54)=29.94$ and 41.65 , respectively, indicating that running speed increased in the goal section across blocks and, as can be seen in Figure 3, that running speed decreased across blocks in the run section. Whether the decrease in speed during acquisition in the run section is due to habituation or some other variable is not clear at the present time. The analysis on start speeds revealed a significant Groups by Blocks interaction, $F(4,54)=4.97$. The simple main effects analysis of the Groups by Blocks interaction indicated that no differences were present between the groups at the beginning of acquisition (Block 1), but the groups were ordered $3 \mathrm{~N}>\mathrm{SA}>\mathrm{CRF}$ during Blocks 2 and 3 . Similar effects were observed for total speeds. Thus, the overall acquisition data (for the 60-trial groups) indicate (in the start and total measures) the presence of a partial reinforcement acquisition effect (PRAE), i.e., partially reinforced subjects running faster than continuously reinforced subjects in the late stages of acquisition.

Overall terminal acquisition performance in each alley section (seen as point $A$ in Figure 4) was examined in separate factorial analyses of variance performed on a block of the last six acquisition trials for each measure. The main effect for Level of Training was significant only in the run section, $F(1,54)=5.04$, with the 12-trial groups running faster than the 60-trial groups, while the main effect for Schedules was significant only in start, $F(2,54)=$ 10.04. Post hoc analysis of the Schedules main effect (using the Tukey procedure) led to the same general conclusion as did the analysis of the 60-trial groups, i.e., a PRAE occurred (at least for the $3 \mathrm{~N}$ groups) in both the start and total speed measures; specifically, in start, $3 \mathrm{~N}>\mathrm{SA}=\mathrm{CRF}$ and, in total, $3 \mathrm{~N}=\mathrm{SA}, 3 \mathrm{~N}>\mathrm{CRF}$, and $\mathrm{SA}=\mathrm{CRF}$. The pattern of results for total speeds was generally the same as for start speeds, except where noted, for both acquisition and extinction.

Extinction. A factorial analysis of variance was performed on the extinction data (shown in Figure 4) for each speed measure. The results of the start speed analysis indicated that the interactions of Levels by Schedules, $F(2,54)=132.09$, Levels

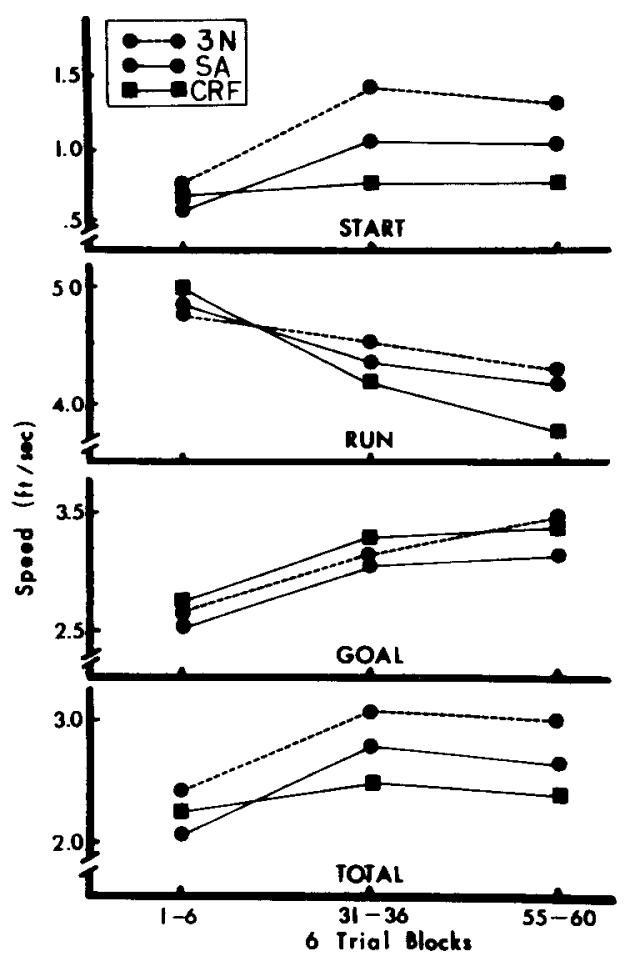

Figure 3. Mean speeds in six trial blocks, for three stages of acquisition: Early (Trials 1-6), middle (Trials 31-36), and late (Trials 55-60). 


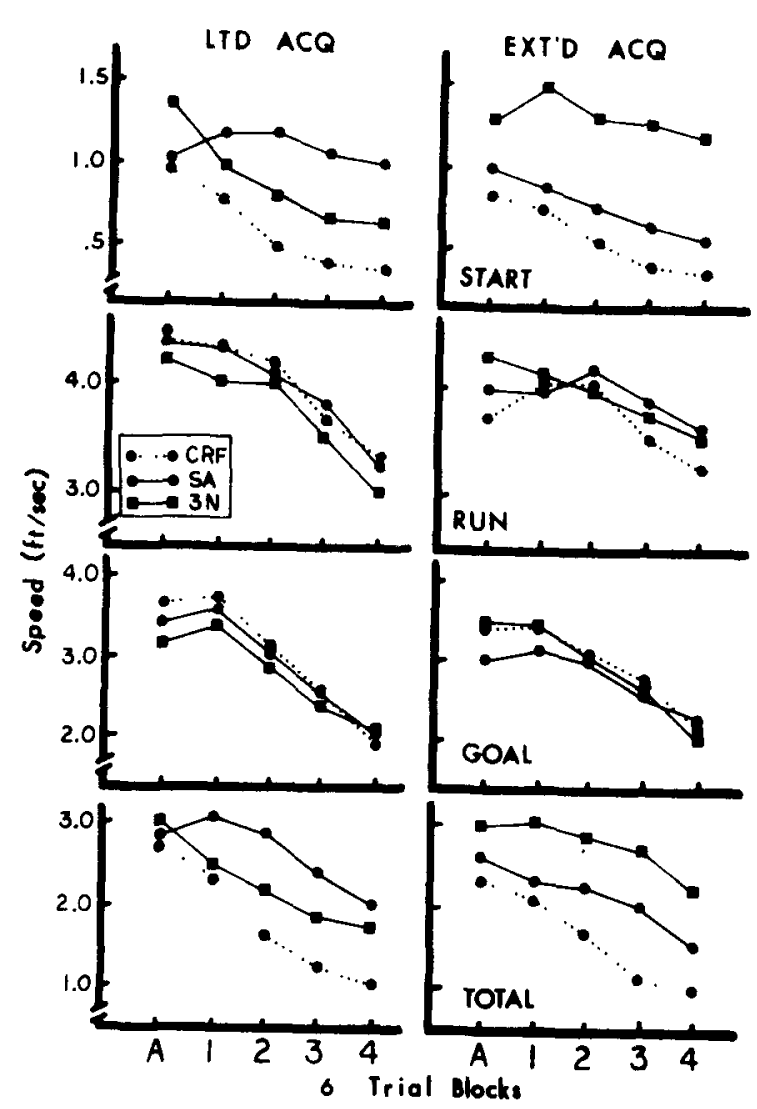

Figure 4. Mean speeds for the last 6 trials of acquisition and 24 trials of extinction, in 6-trial blocks, for subjects receiving limited acquisition training (left panels, limited acquisition) and extended acquisition training (right panels, extended acquisition).

by Days, $F(23,1242)=2.26$, and Levels by Schedules by Days, $F(46,1242)=2.12$, were significant. The Schedules by Days interaction indicated that the PRF schedules produced slower rates of extinction than CRF. Of major interest, however, was the Levels by Schedules interaction, and it was examined using simple main effect tests. These comparisons indicated that the 12-trial groups were ordered SA $>3 \mathrm{~N}>\mathrm{CRF}$ in extinction while the 60-trial groups were ordered $3 \mathrm{~N}>\mathrm{SA}>\mathrm{CRF}$. The significant triple interaction indicated that these differences grew larger over successive days of extinction. It should be noted, however, that the 60-trial groups were also ordered $3 \mathrm{~N}>\mathrm{SA}>\mathrm{CRF}$ at the end of acquisition. Thus, extinction differences may have been an artifact of terminal acquisition performance. In order to evaluate the extinction performance of these groups uncontaminated by terminal acquisition differences, the start and total speed extinction data were transformed to a rate measure (Anderson, 1963) for purposes of reanalysis. The analysis of transformed total speeds revealed results identical to the analysis of raw total speeds, i.e., in terms of resistance to extinction, $3 \mathrm{~N}>\mathrm{SA}>\mathrm{CRF}$. The analysis of transformed start speeds yielded results slightly differ- ent from those from the analysis of raw start speeds, specifically, $3 \mathrm{~N}>\mathrm{SA}=\mathrm{CRF}$ (in the raw speed analysis, SA was more resistant than CRF). This result is not surprising, since the occurrence of patterning during acquisition has been shown to reduce resistance to extinction (e.g., Rudy, 1971). The analysis of the run and goal speed data indicated that the subjects decreased speed over extinction trials and provided some evidence that extended acquisition produced slower extinction across trials than did limited acquisition.

\section{EXPERIMENT III}

The extinction differences for the extended acquisition groups in Experiment II may have been due to a reduction in resistance to extinction in Group SA as a result of the patterning which occurred in acquisition (Rudy, 1971). Accordingly, in the present experiment, $\mathrm{N}$ lengths of 1 and 3 were again used; but in order to preclude patterning, the schedule and percentage of reinforcement were altered slightly so that $\mathrm{N}$ and $\mathrm{R}$ trials did not alternate in the $1 \mathrm{~N}$ condition.

\section{Method}

Subjects. The subjects were 20 male rats, randomly assigned to one of two groups $(\mathrm{N}=10 /$ group $)$.

Procedure. The rats were housed and maintained exactly as were those in Experıment II, and an identical procedure was employed on reinforced and nonreinforced trials. There were two groups in the experiment, both receiving $62 \%$ reinforcement. The schedule of trials for Group IN was RNRNRRNR, and the schedule of trials for Group 3N was RRNNNRRR. These schedules were repeated five tımes, for a total of $\mathbf{4 0}$ acquisition trials. The ITI was $24 \mathrm{~h}$. All rats received 2 reinforced pretraining trials in the apparatus prior to the start of acquisition. Following acquisition training, they received 20 extinction trials, 1 per day for 20 days.

\section{Results and Discussion}

Acquisition. The data for the last 4 days of acquisition were blocked and $t$ tests were performed on the data from each alley section. Group $1 \mathrm{~N}$ was running faster than Group $3 \mathrm{~N}$ in the run, goal, and total measures, $\operatorname{ts}(18)=2.96,1.98,2.34$, respectively. Also, there was no differential responding on the last four $\mathrm{N}$ trials as compared to the last four $\mathrm{R}$ trials $(t<1)$ for Group $1 \mathrm{~N}$.

Extinction. To avoid the possible confound resulting from terminal acquisition differences, the run, goal, and total extinction speeds were transformed to a rate measure (Anderson, 1963). These transformed data, along with the raw speeds from the start section, were then blocked into five four-trial blocks, and separate analyses of variance were performed on each of the measures. The extinction data for Experiment II may be seen in Figure 5. In the start measure, only the main effects for Trial Blocks, $F(4,72)=12.56$, and Groups, $F(1,18)=$ 


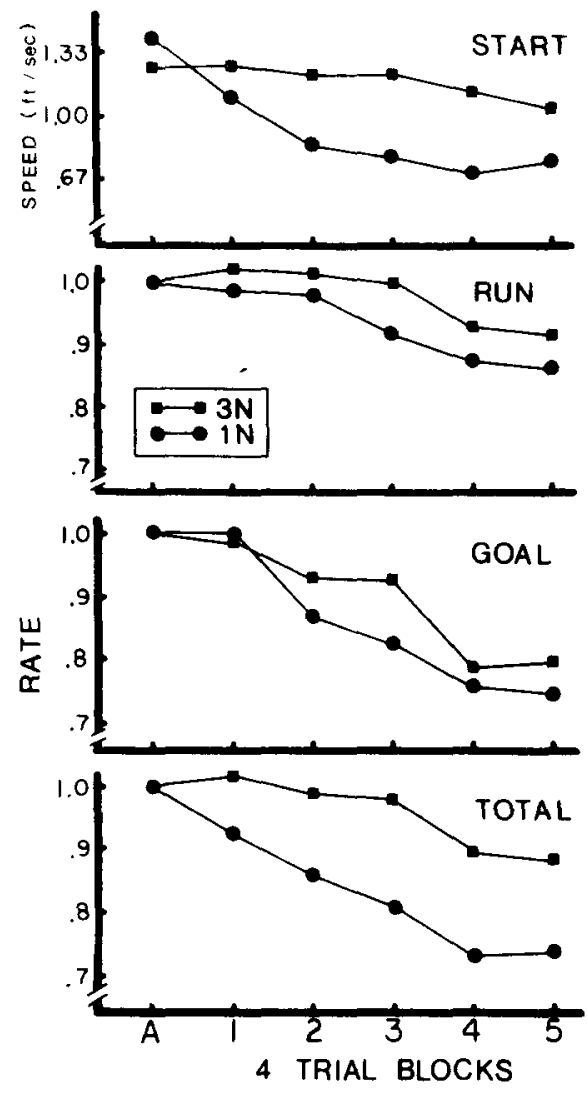

Figure 5. Mean speeds (for the start section) and rate measures (for the run, goal, and total sections) for the last 4 trials of acquisition and 20 trials of extinction, in 4-trial blocks.

40.45 , were significant. (The results for total were similar to those for start.) Group $3 \mathrm{~N}$ was more resistant to extinction than Group $1 \mathrm{~N}$ in the start section. The results of Experiment III thus replicate and support the extinction findings in Experiment II for the extended acquisition condition and also demonstrate that those findings were not due to decreased resistance to extinction in the SA-60 group resulting from patterning in acquisition.

\section{GENERAL DISCUSSION}

The results of the present experiments fit well within a sequential framework and are therefore in agreement with a number of other studies (e.g., Capaldi \& Levy, 1972; Dyck et al., 1974; Seybert, et al., 1974; Wroten et al., 1974) in showing that the boundary conditions of sequential theory may be extended to include certain aversive learning procedures.

It should be noted that the effects of sequential manipulations in the present experiments were limited almost exclusively to the start section of the runway. This pattern of results has also been observed in several other aversive conditioning studies (e.g., Capaldi \& Levi, 1972; Seybert et al., 1974). According to a recent reinforcement level analysis (cf. Capaldi, 1974; Capaidi \& Freese, 1975), "inhibition" generated in the goalbox on nonreinforced trials, either during acquisition or extinction, is an important determinant of performance in and near the goal area, but generalizes very little to earlier segments of the runway. The effects of sequential variables are mediated by memories which are reinstated by startbox cues. Thus, in the present experiments, sequential effects were observed in the start section, where inhibition from the goal area has little effect, but were not observed in the run and goal sections, where goalbox-generated inhibition may exert a much more powerful effect on behavior, even to the extent of obscuring other previously acquired associative tendencies (cf. Capaldi \& Levy, 1972).

\section{REFERENCES}

AMSEL, A. Partial reinforcement effects on vigor and persistence: Advances in frustration theory derived from a variety of within-subject experiments. In K. W. Spence \& J. T. Spence (Eds.) The psychology of learning and motivation (Vol. 1). New York: Academic Press, 1967.

Anderson, N. G. Comparison of different populations: Resistance to extinction and transfer. Psychological Review, $1963,70,162-179$.

CAPALDI, E. J. A sequential hypothesis of instrumental learning. In K. W. Spence \& J. T. Spence (Eds.), The psychology of learning and motivation (Vol. 1). New York: Academic Press, 1967

Capaldi, E. J. Memory and learning: A sequential viewpoint. In W. K. Honig \& P. H. R. James (Eds.), Animal memory, New York: Academic Press, 1971.

CAPAld, E. J. Partial reward either following or preceding consistent reward: A case of reinforcement level. Journal of Experimental Psychology, 1974, 102, 954-962.

Capaldi, E. J., \& Freese, M. R. Alley section effects of magnitude of partial reward after extensive acquisition training. Bulletin of the Psychonomic Society, 1975, 5, 294-296.

Capaldi, E. J., \& Levy, K. J. Stimulus control of punished reactions: Sequence of punishment trials and magnitude of reinforcement. Learning and Motivation, 1972, 3, 1-19.

Capaldi, E. J., \& LYNCH, D. Patterning at 24-hour ITI: Resolution of a discrepancy more apparent than real. Psychonomic Science, 1966, 6, 229-230.

Dyck, D. G., Mellgren, R. L., \& Nation, J. R. Punishment of appetitively reinforced instrumental behavior: Factors affecting response persistence. Journal of Experimental Psychology, 1974, 102, 125-132.

Franchina, J. J. Intertrial intervals and shock schedules in escape training. Journal of Comparative and Physiological Psychology, 1969, 67, 510-515.

Gonzales, R. C., \& Bitterman, M. E. Spaced-trials partial reinforcement effects as a function of contrast. Journal of Comparative and Physiological Psychology, 1969, 67, 510-515.

HulSE, S. H. Amount and percentage of reinforcement and duration of goal confinement in conditioning and extinction. Journal of Experimental Psychology, 1958, 56, 48-57.

Jobe, J. B., \& Mellgren, R. L. Successive nonreinforcements (N-length) and resistance to extinction at spaced trials. Journal of Experimental Psychology, 1974, 103, 652-657.

Meligren, R. L., Nation, J. R., \& Wrather, D. M. Magnitude of negative reinforcement and resistance to extinction. Learning and Motivation, 1975, 6, 253-263.

Mellgren, R. L., \& Seybert, J. A. Resistance to extinction 
at spaced trials using the within-subject procedure. Journal of Experimental Psychology, 1973, 100, 151-157.

Foввіns, D. Partial reinforcement: A selective review of the alleyway literature since 1960. Psychological Bulletin. 1971, 76, 415-431.

Fudy, J. W. Sequential variables as determiners of the rat's discrimination of reinforcement events: Effects on extinction performance. Journal of Comparative and Physiological Psychology. 1971, 77, 476-481.

Seybert, J. A., Mellgren, R. L., \& Jobe, J. B. Sequential effects on resistance to extinction at widely spaced trials. Journal of Experimental Psychology, 1973, 101, 151-154.

Seybert, J. A.. Mellgren, R. L., Jobe, J. B., \& Eckert, E. Sequential effects in discrete trials instrumental escape conditioning. Joumal of Expermental Psychology, 1974, 102. $473-483$.

Surridge, C. T., \& Amsel, A. Acquisition and extinction under single alternation and random partial-reinforcement conditions with a 24-hour intertrial interval. Journal of Experimental Psychology, 1966, 72, 361-368.

Wroten, J. D., Campaell, P. E., \& Clevieland, C. T. Response persistence following intermittent punishment and partial reinforcement: Effects of trial sequence. Learning and Motivation, 1974, 5, 118-127.

(Revision received March 15, 1976; accepted April 19, 1976.) 